\title{
Double coupling: modeling subjectivity and asymmetric organization in social-ecological systems
}

\author{
David Manuel-Navarrete $^{l}$
}

\begin{abstract}
Social-ecological organization is a multidimensional phenomenon that combines material and symbolic processes. However, the coupling between social and ecological subsystem is often conceptualized as purely material, thus reducing the symbolic dimension to its behavioral and actionable expressions. In this paper I conceptualize social-ecological systems as doubly coupled. On the one hand, material expressions of socio-cultural processes affect and are affected by ecological dynamics. On the other hand, coupled social-ecological material dynamics are concurrently coupled with subjective dynamics via coding, decoding, personal experience, and human agency. This second coupling operates across two organizationally heterogeneous dimensions: material and symbolic. Although resilience thinking builds on the recognition of organizational asymmetry between living and nonliving systems, it has overlooked the equivalent asymmetry between ecological and socio-cultural subsystems. Three guiding concepts are proposed to formalize double coupling. The first one, social-ecological asymmetry, expands on past seminal work on ecological self-organization to incorporate reflexivity and subjectivity in social-ecological modeling. Organizational asymmetry is based in the distinction between social rules, which are symbolically produced and changed through human agents' reflexivity and purpose, and biophysical rules, which are determined by functional relations between ecological components. The second guiding concept, conscious power, brings to the fore human agents' distinctive capacity to produce our own subjective identity and the consequences of this capacity for social-ecological organization. The third concept, congruence between subjective and objective dynamics, redefines sustainability as contingent on congruent relations between material and symbolic processes. Social-ecological theories and analyses based on these three guiding concepts would support the integration of current structuralist-functionalist methods, which sufficiently and appropriately characterize ecological organization, with ethnographic and narrative methods exploring human intentionality, reflexivity, and biographical development.
\end{abstract}

Key Words: congruence; conscious power; coupled nature-human systems; social-ecological organization; subjectivity; sustainability;

\section{INTRODUCTION}

Look at these trees. Look at these birds in the sky. Whenever I go to take care of the crops, I see that they are in perfect harmony with nature. They have found their place in the divine design. On the other hand, I have to sweat to keep my life under control. For what reason do the gods treat the birds and trees with so much more generosity? Paulo Coelho, Dialogues with Buddha

Social-ecological systems (SESs) are structurally determined by cross-level and cross-scale interactions (Allen and Hoekstra 1992, Gibson et al. 2000). In line with this, resilience thinking applies system-based, structuralist, and functionalist frameworks that originate in ecology, such as the adaptive cycle, to frame the analysis of social-ecological dynamics. This reflects the assumption that social and ecological self-organization are isomorphic or equivalent, e.g., both made up of functional components and relations, and therefore SESs are organizationally homogeneous (Holling 2001, Low et al. 2003). Such an assumption allows focusing on complex interactions, involving for instance feedback loops or thresholds, between organizationally equivalent components (or agents) be they physical, biological, or human (Horan et al. 2011). Organizational homogeneity effectively depicts nonhuman SESs, such as ant colonies, or social-ecological situations where functionalist models of the individual, e.g., rational-choice behavior, can realistically characterize human agency (e.g., Miller and Page 2009), such as markets or resource-based situations with stable rules. However, it fails to accommodate culture, politics, and subjective processes associated with reflexivity and intentionality (Manuel-Navarrete and Buzinde 2010, Brown and Westaway 2011). Subjectivity is particularly relevant in social-ecological situations characterized by changing and ambiguous rules, where individuals have the power to create new rules, reinterpret existing rules, and reflexively transform their identity as a result. In this paper I support a conceptualization of SESs based on foregrounding organizational heterogeneity and the role of subjectivity and reflexivity within these systems. This foregrounding can potentially redirect resilience research agendas toward: (1) incorporating sophisticated accounts of human agents' unique power to shape both symbolic and material processes in SESs, (2) reconceptualizing social-ecological coupling as an asymmetric process, and (3) redefining sustainability as a measure of congruence between material and symbolic processes.

The study of human-environmental relations has long been a part of cultural, human, and political ecology research traditions (Hollingshead 1940, Turner 2002, Turner and Robbins 2008), as well as of more applied research fields (e.g., Mazoyer and Roudart 2006). However, the formalization of the term "social-ecological system" was explicitly formulated in late 1980s. Gallopín et al. (1989) built on theories of dissipative structures (Nicolis and Prigogine 1977) and resilience (Holling 1973) to describe "socialecological systems" as two subsystems connected through causal circuits, including both human actions affecting ecological subsystems as well as ecological effects on the social subsystem. These authors described human actions as the sum of actions by 
diverse actors who are driven by specific motivations, hold distinctive perceptions about the environment and are dependent on social systems' internal functioning. Gallopín et al.'s (1989) original framework sought a balance between the two subsystems, in an attempt to level them epistemologically. Their focus, which subsequent researchers have followed, was on the exchanges and feedbacks between the two subsystems, and the literature has neglected to investigate whether these two subsystems might exist in an embedded relationship. Moreover, even though the two subsystems are presumed to be ontologically and epistemologically equal, most analyses have privileged the ecological perspective (Folke et al. 2011, Brown 2014).

Early formalizations revealed problems with the demarcation of SES boundaries. On the one hand, the two subsystems may not match spatially, except perhaps in the case of homogeneous local societies highly dependent on a single ecosystem as found on small islands. On the other hand, social and ecological boundaries are distinct in their determinants. Biophysical processes generally define ecological (bona fide) boundaries, while human demarcation defines social (fiat) boundaries (Smith and Varzi 2000). Subsequent elaborations have relied on the boundary of one of the subsystems, usually the ecological one, to guide the drawing of boundaries for a whole SES (Alessa et al. 2009). The application of this ecological bias commonly starts with the preanalytical choice of a specific ecosystem, or resource, as the focal unit of analysis, proceeding to identification of the social processes affecting the dynamics of the focal unit (Ostrom 2009). In this way, researchers conceive of social processes and actions as ecologically bounded by concepts such as a "community of resource users" (Li 2001). This approach was popularized by Berkes and Folke who concisely defined it as the "investigation of social and ecological linkages in selected ecosystems" (Berkes and Folke 1998:3). This extremely productive line of inquiry bundles ecosystems, complexity theory, and resilience thinking into the study of community-based conservation, local governance, adaptation, and sustainability (Chapin et al. 2010). However, the focus on ecosystems and natural resources severely limits that which counts as social-ecological.

Proposals to strengthen the analysis of the social side of resilience have multiplied in the last decade (Keck and Sakdapolrak 2013, Fabinyi et al. 2014). These proposals seek hybrid and more evenhanded representations of SESs that combine mainstream social-ecological knowledge with specific social science concepts and approaches. For instance, Armitage et al. (2012) explore the intersection between resilience and social well-being approaches. These authors discuss the different emphases of each approach, where social well-being emphasizes the material, relational, and subjective aspects of people's lives. They conclude that the complementarity of social science and resilience approaches allows a richer understanding of social-ecological complexity. Similarly, Berkes and Ross (2013) investigate the common conceptual ground between two established strands of research: SES resilience, and the social sciences' fields of psychology development and mental health. These authors discuss and partly integrate these two strands through an assessment of each strand's strengths and weaknesses in particular situations. These proposals effectively combine key ecological and social concepts and approaches but do not challenge nor revise ecologically biased conceptualizations of SESs (Cote and Nightingale 2012, Davidson 2013).
I propose a conceptual strategy to overcome ecological biases through (1) recognizing asymmetry as a main organizational principle of social-ecological coupling and (2) highlighting the key role of psychosocial and subjective dynamics in SESs (Trosper 2005, Brown and Westaway 2011). The three guiding concepts presented below are introduced to reformulate SESs as doubly coupled. On the one hand, there is material coupling between ecological and social dynamics. This recognizes the physical basis for social relations and the unavoidable constraints imposed on them by human biology. On the other hand, these material socialecological dynamics are in turn coupled with subjective processes. This recognizes that human purpose and its associated cognitive dynamics are not entirely captured by biological and ecological functioning.

The paper starts by discussing each guiding concept to then formulate an alternative way of representing social-ecological organization in terms of double coupling. The first guiding concept, social-ecological asymmetry, builds on Schneider and Kay's (1994) ecological applications of thermodynamics to establish that, much as the capacity of ecological self-organization to create persistent structures separates it from physical-chemical self-organization, socio-cultural self-organization stands apart from ecological self-organization because of reflexivity (Trosper 2005, Stengers 2010). The second concept, conscious power, identifies self-awareness and reflexive agency as main driving forces of social-ecological organization and change, and highlights the need to effectively account for people's perspectives and biographic trajectories in SES theory and analysis. Conscious power points to an agent's capacity to purposefully seek a change of his or her position in a social-ecological structure. Third, the concept of congruence between objective and subjective dynamics establishes that sustainability is an outcome of the interdependence between external and intrapersonal processes. Thus, sustainability approaches purely based on material outcomes or structural change are significantly incomplete. Sustainability assessments and interventions need to account for the coupling between material-structural change, and the symbolic dynamics through which human agents create meaning about their individual life trajectories. This is consistent with resilience frameworks in which sustainability is seen as implicating subjective preferences about which system states are desirable (e.g., Carpenter et al. 2001).

\section{ORGANIZATIONAL ASYMMETRY BETWEEN ECOLOGICAL AND SOCIO-CULTURAL SUBSYSTEMS}

Socio-cultural and ecological subsystems are not organizationally equivalent because human agents shape social organization by reflexive and relatively autonomous decisions made about reproducing or challenging social rules. Ecological organization is still mechanistic in the sense that it arises from the functional interaction of the ecosystem's components, each largely behaving under given rules and according to genetically inherited attributes. Unlike physical systems, the components of living systems create, and are functionally dependent on, their ecological context, and have little functional meaning outside that context (Rosen 1985). Applications of nonequilibrium thermodynamics to biology and ecology brought about new understandings of living systems as dissipative structures that change irreversibly according to a certain directionality or final causality (Jørgensen and Svirezhev 2004, Stengers 2010). This understanding revealed that living systems self-organize to harness and degrade available physical-chemical 
gradients of "exergy," i.e., high quality/useful energy. Schneider and Kay (1994) empirically explored the idea, which Polanyi (1968) had originally devised, that ecological self-organization is shaped by life's need to impose sets of boundary conditions on physical-chemical processes. Thus, the imposition of boundary conditions with the final cause of harnessing energy and material resources is a defining ability of living systems. Furthermore, the drive to impose boundary conditions translates into the creation of stable local states, ranging from organisms to whole ecosystems, which allows living systems to stay temporarily away from thermodynamic equilibrium (Allen et al. 2001).

Living systems self-organize as a dissipative mechanism that resists the "thermodynamic equilibrium movement," which is constantly pushing these systems away from self-produced and locally stable states in which the system maximizes exergy dissipation (Kay 2000, Fath et al. 2004). Exergy gradients also sustain nonbiological self-organizing dissipative structures, e.g., tornadoes, but these abiotic structures cannot harness the gradients that produce them to become locally stable. Living systems are self-produced and capable of (1) incorporating matter in the self-organizing process to sustain and create stable dissipative structures, (2) using stored genetic information to recreate self-organization without building it from zero after it broke down, and (3) enhancing survivability by manipulating or shaping exergy gradients and environments (Kay et al. 1999). These unique capabilities mean that living systems operate asymmetrically in relation to nonliving systems and at a higher level of organization and complexity. Genetic memory sustains the dissipative organization over time without having to restart new dissipative events via stochastic environmental conditions. Asymmetries manifest in new patterns of organization that are consistent with, but irreducible and nonequivalent to, physicalchemical patterns. In fact, living systems have evolved in ways that ensure the sustainability of biological and ecological dissipative structures in response to fluctuating environments. They can be seen as dissipative pathways with encoded memories (Kay 2000).

Acknowledgment of asymmetrical relations between physicalchemical and ecological self-organization has been fundamental for resilience thinking (Levin 1998). Building on the empirical observation that ecosystems capture more energy and make better use of it as they mature, Schneider and Kay (1994) hypothesized that ecosystems self-organize and "ecologically evolve" in the direction of finding better and faster ways of dissipating available exergy gradients (Minkel 2002). Although Darwinist evolution may apply to organizationally closed organisms, evolution cannot select for ecosystems in the way it selects for genetically encoded organisms. However, this does not mean that ecological selforganization is purely stochastic, or mechanistic, in the same sense as storms or lasers (Kay 2000). Physical-chemical selforganization is reactive and ephemeral; it spontaneously emerges in the presence of exergy gradients, in fact, as the direct consequence of these gradients. "Lower" physical-chemical organization is not less important or fundamental, but its dynamics are simpler because of lesser autonomy from the environment. Physical-chemical systems do not evolve because their organization is contingent upon a specific environmental gradient and does not persist once that gradient dissipates.
It is ironic that although resilience thinking builds on the recognition of organizational asymmetry between living and nonliving systems, it has failed to recognize a parallel asymmetry between ecological and social domains. This recognition is perhaps hindered by the fact that some invertebrate species, such as ants or bees, display (biologically determined) social behavior. However, these basic forms of social interaction are not equivalent to socio-cultural dynamics supported by symbolic processes that are embodied in self-conscious beings. As argued by Polanyi way before the popularization of resilience thinking: "[O]nce it is recognized [...] that life transcends physics and chemistry, there is no reason for suspending recognition of the obvious fact that consciousness is a principle that fundamentally transcends not only physics and chemistry but also the mechanistic principles of living beings." (1968:1310). Resilience and Holling's (1973) adaptive cycles have a heuristic value to explore structural dynamics in SESs, yet the extrapolation of ecological resilience to socio-cultural systems, and by extension to SESs as a whole, requires caution. Resilience researchers have recently started to acknowledge the need for more sophisticated theoretical and analytical distinctions between the two subsystems. The full theoretical and practical consequences of such distinctions, however, are yet to be explored (Crane 2010, Davidson 2010, Cote and Nightingale 2012). Even though Holling (2001) correctly identified foresight, intentionality, communication, and technology as unique to human systems, resilience scholars have overlooked the theoretical and methodological challenges of applying the adaptive cycle and panarchy models to asymmetric social-ecological systems. Perhaps influenced by systems thinking epistemologies (e.g., Checkland 1981) the dominant assumption is that both ecological and social systems are adaptive systems composed of functional parts properly linked to others.

As all organisms, human agents must survive and be materially viable and resilient, but they do so in accordance with symbolic and meaningful structures or schemes partly of their own devising. Meaning-symbolic structures emerge from cognitive processes and provide the basis of socio-cultural selforganization. This does not mean that ecological organization or nonreflexive species are of less value. In fact, they are more fundamental because they provide the material basis for the emergence of the symbolic dimension. However, reflexivity provides individual agents with unique powers to autonomously rethink and intentionally influence material structures, hence creating an asymmetric coupling. For instance, human agents are particularly competent to (1) simultaneously occupy multiple positions in social-ecological structures, (2) change positions or reset the functions attributed to each position, and (3) make some positions or functions evolve into something else. Structuralist or functionalist frameworks of analysis, which might explain ecological resilience, do not suffice for social-ecological organization because of the variability and fluidity that originate from reflexive agency (Trosper 2005, Manuel-Navarrete and Buzinde 2010).

\section{CONSCIOUS POWER}

Social-ecological institutional analysis focuses on human behavior, decision making, and material outcomes. A major concern is to develop a broad theory of how humans tend to behave in diverse ecological situations. However, this is challenging because humans do not have fixed characteristics; 
they adapt and change over time (Ostrom 2005). The concept of conscious power departs from a focus on situational behavior to emphasize human capacities to consciously shape the situations in which they operate and behave. As conscious beings we have freedom to shape our mental processes, which endows us with autonomy to influence SESs symbolically and materially. Intention, purposiveness, and even emotions are not exclusively human experiences because some forms of nonhuman animals can and do have a role in the formulation of their individuality. However, human subjectivity includes individuals' ability to design and strategically change social rules with the goal of shaping the power relations that impinge upon them (Lotka 1945, d'Aquino and Bah 2013). Therefore, subjectivity includes the political aim of influencing structural change in a desired direction. Although biophysical structures make human cognitive abilities possible, biophysics does not entirely dictate our cognitive pathways (Dennett 1993). Rather intrapersonal forces such as the meaning of life-long trajectories, or the coherence of our life stories, which we build ourselves through experiencing the world, feed subjectivities and help shape who we become (Archer 2003).

Recognizing the key influence of conscious power further challenges structuralist biases in social-ecological research. Representing social systems through sets of positions and rules of interaction tends to support functionalist analyses that, although useful to simulate outcomes, overlook the subjective and political processes involved in the creation and evolution of these positions and rules. Common pool resource (CPR) literature has effectively developed functionalist representations via the "action situation" construct. The Institutional Analysis and Development Framework (IAD) is a popular framework in CPR literature that conceptualizes human agents as actors operating in action situations (Ostrom 2005). These actors assess the outcomes that result from using resources and interacting with other actors, and decide whether to comply with existing rules, or not, to maximize preferred outcomes. Successful CPR systems are those that establish rules (and incentives to comply with these rules) that lead to interactions and behaviors that, subsequently, yield sustainable outcomes. Operational-level analysis has proven effective in modeling traditional resource-based systems highly dependent on local ecosystems that are characterized by relatively slow change. However, politics and culture affect even the simplest CPR system, including, for example, ethnic, gender, and caste identities of participants (Agrawal 2003). The cultural and political contexts of action situations were part of the IAD framework since its inception (Ostrom 1990), but they have slipped out of focus over time despite their particular prominence in intensely humanized and highly complex SESs such as urban or agriculture systems (Clement 2013).

Social-ecological research needs to include the ethnographic and narrative study of agents' life trajectories, including deliberate involvement in the construction of identities and social positions. In turn, social researchers need to explore ways of objectivizing the subjective dimension, without obliterating the subject, and provide general rules about meaning-making processes so that subjectivity can be effectively integrated within systems research. As Bromley (2012) suggests: "it is the social construction of that ecosystem-its shared mental objectification-that will be decisive in terms of institutional arrangements for addressing issues of global governance." Promising developments in this direction include the study of "mind maps" and "mental models" (Glaser 2006, Jones et al. 2014). The concept of conscious power emphasizes that individual humans are constantly free to challenge social structures both explicitly through political action, and implicitly through the construction of subjectivities. Identities and social positions are not relatively stable starting points from which a system's self-organization unfolds. Instead, change and development in identities and positions occur habitually, rapidly, and unpredictably, as part of the very process of social-ecological organization. Changes in individual or collective identities have a subjective component. That is, they involve individual or collective subjects who are faced with fields of power within which they may choose and realize several identifications. However, subjective choices are not independent from material and informational dynamics within SESs.

Conscious power is not the only cognitive force influencing SESs' dynamics (Beratan 2007). Unconscious cognitive power can be formulated as a fundamental force of biological and social organization that is exerted by all sentient beings. Unconscious cognitive processes were central to both Bateson's "ecology of mind" (1972), and Maturana and Varela's systems perspective on biology and cognition (1980). For Bateson (1972), unconscious "mental" processes organize the entire living world and allow for the coupling between organisms and systems. In his view, all organisms and systems are "minds" capable of unconscious cognition. Bateson's biologistic explanation of humanenvironmental coupling turns my concept of social-ecological asymmetry upside-down. He downplays consciousness by arguing that it is a limited and biased component of our larger unconscious mind. Consciousness cannot ensure the coupling of humans and environment because it is only capable of processing partial and distorted (subjective?) information. Only unconscious mental processes have access to the "evolutionary wisdom" that enable from organisms to systems to adapt to environmental stimuli through coordinating physiological, genetic, behavioral, or functional responses.

Maturana and Varela (1980) proposed that cognition is not exclusive to the brain, mind, or consciousness, but a quality of life itself. They explained living systems as the product of reciprocal relationships between (1) an organism's internal organization and (2) the need to maintain structural coherence with the environment. In this view, all organisms generate "meaning" as they establish viable patterns of interaction with the environment by regularly responding to stimuli and phenomena (see also Lewontin 1998). At the same time consciousness is a particular form of cognition that cannot be reduced to neuronal processes or nervous system dynamics (Thompson and Varela 2001). According to Maturana (2008), human consciousness is related to our ability to use language to refer to entities that are external to us. As "languaging beings" we have the power to generate "any new world that we may language into existence" (Maturana 2002:30). Consciousness emerges through our recursive and reciprocal interrelationships with our environment as we imagine alternative configurations of interrelationships and choose which ones to realize.

The idea of reciprocal interactions between organisms and environment does not imply symmetry (Thompson and Varela 2001). Maturana and Varela's (1980) approach to consciousness 
is consistent with the idea of double coupling presented in this paper. On the one hand, these authors challenge any rigid boundaries between biology and consciousness, but on the other hand they acknowledge that consciousness is an emergent process conferring some autonomy on self-conscious beings, be they human, primates, or dolphins. The point here is that we are both self-conscious, and material. Our materiality makes us transitory while "self-consciousness is the opening for reflective autonomy and freedom" (Maturana 2002:31). The autonomy of intrasubjective processes from social-ecological materiality problematizes our understanding of how social-ecological coupling actually works. If subjectivity is an emergent phenomenon, then what role does it play in the coupling (or decoupling) of social and ecological processes? Which aspects of social organization can become truly autonomous from ecological processes? Which ones are structurally constrained or somehow determined by material processes?

\section{SUSTAINABILITY AND CONGRUENCE BETWEEN SUBJECTIVE AND OBJECTIVE DYNAMICS}

The two concepts discussed above invite understandings of socialecological sustainability that focus on the challenge of maintaining congruence across asymmetrical levels of organization; that is, across subsystems that change according to distinctive organizational principles. Resilience scholars have contributed to system-based conceptualizations of sustainability. They assess the sustainability of different types of SESs in terms of system properties. These properties include adaptability; the system's capacity to remain in a "good" stability domain, i.e., "good resilience," as well as the system's transformability or capacity to shift in directions that get it out of a rigidity trap, i.e., "bad resilience," while preserving its identity (Olsson et al. 2014). However, the question of what states or transformations should count as sustainable (for whom?) cannot be objectively resolved by merely invoking generic systems' functions (Trosper 2005). A system's capacity to deal with future disruptive change or to respond to new opportunities is hardly ever desirable for everyone. Social-ecological sustainability requires incorporating into the analysis subjective ideas about what counts as desirable change. Incorporating this subjective dimension would contribute to the avoidance of fair criticisms that applying functional systems' properties, such as resilience, to social subsystems leads to unwarranted emphases on consensus, agreement, harmony, and compatibility, while downplaying conflict (Hornborg 2009). Furthermore, as discussed in the previous section, human agents can consciously seek to steer a SES (Trosper 2005). We need to understand the role that thoughts and feelings about desirable and sustainable states and pathways play in system-level dynamics (Hukkinen 2012). Such thoughts and feelings are themselves dynamic, changing subjectively along the autobiographic development of autonomous agents who are constantly interacting (and struggling) with other agents and their environment (ManuelNavarrete 2013). The concept of congruence between subjective and objective dynamics highlights that sustainability transcends materiality.

Social-ecological institutional analysts conceptualize sustainability in terms of outcomes from actions situations (Ostrom 2005). A main goal is to avert "perverse outcomes." Perversity evokes the idea of being unacceptable, as well as unintended and undesired. However, there are no universal standards of acceptability and desirability. Power relations, conflict, and the subjective process through which different actors may determine what is acceptable, desirable, sustainable, or perverse need to be brought to the fore. Neither social-ecological institutional analysts nor resilience scholars have focused their analytical lenses on the genesis of preferences, political processes, or the subjective dynamics as vigorously as social sciences have. One notable exception is Agrawal's Foucauldian exploration of environmental subjectivities in the context of CPR analysis (Agrawal 2005). The concept of congruence between subjective and objective dynamics seeks to support a more integrated framework that defines sustainability as the interplay of ecological, operational, political, cultural, and personal dynamics (Fig. 1).

Fig. 1. Organizational congruence between asymmetric dynamics in social-ecological systems.

Levels of Organization Types of Dynamics

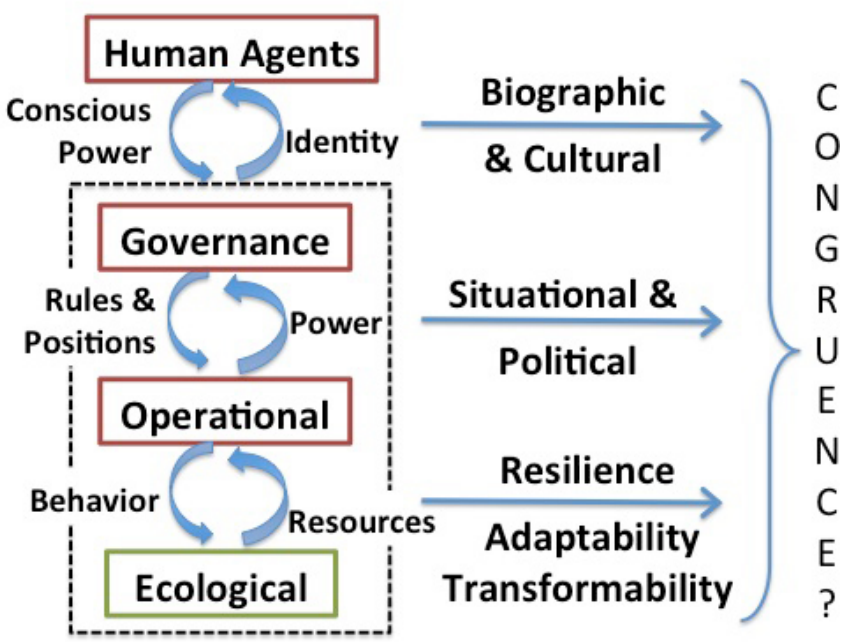

Sustainability science has implicitly recognized social-ecological congruence, typically framing it as the gap between knowledge (symbolic dimension) and action (material dimension; van Kerkhoff and Lebel 2006). Resilience scholars have also addressed aspects of social-ecological congruence through the investigation of "fit" between institutions and ecosystems (Folke et al. 2007, Farrell and Thiel 2013). "Fit" refers to the congruence of ecological dynamics with institutional arrangements. Resilience scholars propose that adaptively realigning governance structures will address the incongruence (e.g., Olsson et al. 2007). However, social-ecological congruence also depends on political and cultural processes giving rise to specific sustainability challenges, e.g., social inequality, beyond institutional fit. For instance, members of a fishing community may also be members of the community's municipal government, as well as an ethnic or religious cohort. In such cases, they will need to find ways of making these multiple positions and identities somehow congruent, thus bringing the problem of fit to the intra-personal dimension (Hukkinen 2012). Few ecological systems have these blurring of levels (though an omnivore may occupy several positions in a trophic chain). Biological organisms attain structural and functional congruence with the ecosystem as a 
result of their evolutionary development as a species, and for the most part independently of individual life trajectories (Stengers 2010).

The mobility and conscious power of humans within socialecological systems pose special analytical challenges for sustainability because of the multiple forms of congruence that are required to reconcile tensions arising from competing identities and subjectivities, changing positions, and simultaneously holding multiple positions. Social-ecological research needs to identify, describe, and measure these (in)congruencies (Bromley 2012). Autobiographical and ethnographic research needs to be effectively combined with system-level research. An adjustment of the major research questions asked might also be suitable. For instance, questions about material sustainability can be complemented with the interrogation of what it means to live a sustainable life in terms of the type of relationship that one has to establish to oneself. Life stories may provide valuable accounts of agency and data about an agent's dynamic structural congruence within SESs. Individual development in humans is not random, or overwhelmingly determined by genetics and environmental structures (Lewontin 1998). Individuals improvise their identities as they make their way through the world. Sustainability depends on the ability of both nonhuman and human agents to create congruent relations within and between levels of organization. In the social subsystem, congruence may be as much symbolic as material (Crane 2010). It depends on reflexivity and the ability of human agents to internally reconcile their material interactions. As we make decisions and take actions we build (in)congruence among (1) personal trajectories of identification, (2) the requirements of our social position that we may have contributed to create and shape, (3) the requirements of positions to which we aspire and (4) coupled ecological and social dynamics in which we participate.

\section{DOUBLE SOCIAL-ECOLOGICAL COUPLING}

The three concepts introduced in this paper challenge symmetric representations of social-ecological coupling. Figure 2 depicts the basic structure of double coupling. This structure includes symmetric (horizontal) coupling made of material as well as informational processes (Fig. 2, A), and asymmetric (vertical) coupling between material, and symbolic-subjective processes. The former includes what Archer (1995:180) calls systems "without a knowing subject," in which information can be separated from those who know it. The former is "culture with a knowing subject"; framed by people's biographies and the power relations within which subjectivities are embedded. On the upward direction of asymmetric coupling, individuals interact with material systems to actualize personal meaning systems about the relational matrix within which their lives unfold (Fig, 2, B). The outcome is "subjective experience," or the ways in which people come to think of themselves, others, and the material. This subjective experience is mediated by the "stories told" (to ourselves and others) "in natural language," and by "reflexivity." On the downward direction (Fig. 2, C), consent or dissent with material regimes is a matter of choice and political action (of "human agency") when regimes are nontotalitarian. Socialecological models (Fig. 2, D) are symbolic-scientific systems that seek to mimic the observed, or hypothesized, material dimension of actual SESs in, debatably, objective ways (Rosen 1985). Thus, these models effectively underplay the role of subjectivity in both observed social-ecological dynamics, and the very practice of modeling these dynamics. However, model outcomes have to be typically translated into stories to enter vertical coupling and have material effects via human agency.

Fig. 2. Schematic representation of double coupling in socialecological systems.

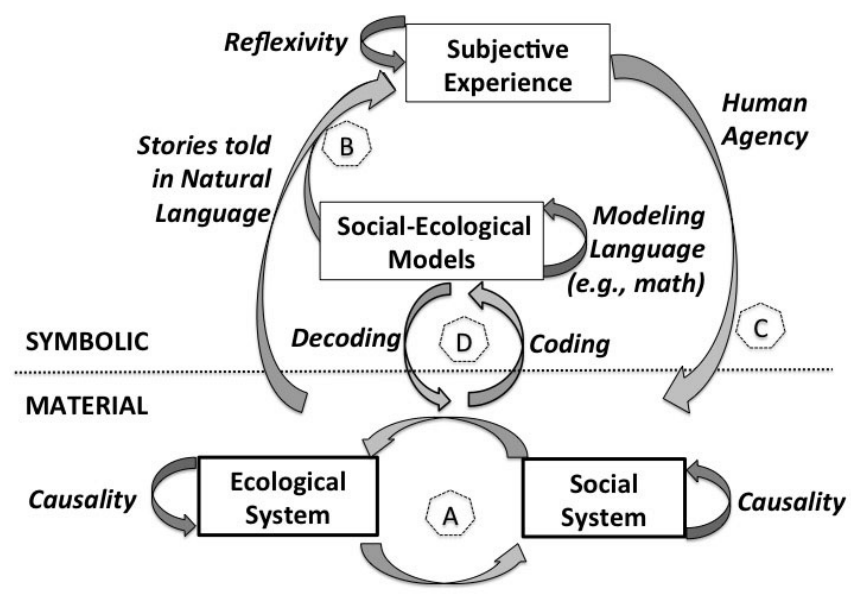

We influence social-ecological systems through our behavior, but also through the stories we tell (Geertz 1984, Goldstein et al. 2015). Doubly coupled social-ecological systems imply interdependencies between inner world, e.g., dreams, fantasies, or emotional responses, and outer world, e.g. social and biophysical phenomena. Social-ecological researchers need to link the intrapersonal, e.g., a particular trajectories unique to a person, with the material unfolding of interacting living and social systems (Manuel-Navarrete et al. 2004). Persons are not exclusively bounded, unique, cognitively integrated entities or utterly constructed by social discourse and biophysical processes. Instead we are relatively autonomous, but fundamentally coupled to material social-ecological dynamics.

Figure 2 does not pretend to provide a final, universal representation of double coupling. Resilience scholars can draw on social theory and philosophical debates for alternatives that may fit the needs of each particular case. Formalizing socialecological systems as doubly coupled entails a more nuanced consideration of the role of the observer, including scientists (Allen et al. 2001). Resilience thinking has greatly contributed to our capacity to interpret and engage with social-ecological complexity, e.g., promoting nonlinear thinking, and new ways of acting upon these subjective capacities, e.g., supporting adaptive management. Acknowledging asymmetrical coupling may help to underscore the fact that resilience scholars are subjects, inherently involved in the social-ecological dynamics they study.

\section{CONCLUSIONS}

Social-ecological resilience research can benefit from explicitly distinguishing ecological self-organization, which is driven by a combination of thermodynamic laws and functional networking, and socio-cultural self-organization, which is driven by sociopsychological factors. Resilience is a functional property that provides ecosystems with stability in the face of environmental 
change. Schneider and Kay (1994) found that ecosystems inherently seek stability via their propensity to dissipate as much exergy as possible, which in turn promotes species survivability and the systems' sustainability. The idea that we can promote ecological sustainability through managing ecosystems' resilience revamped conservation science and practice. Initial excitement led to a sweeping extension of resilience concepts to SESs in general, but thermodynamic laws do not structure social systems in the way that they structure ecological systems. The internal organization of SESs is asymmetrical because social dynamics depend on subjective processes through which human agents can consciously aim to steer the overall system. However, this steering is often nondeterministic and cannot be conceptualized entirely through reference to system function. It is self-reflexive, and dialectical, the result of humans acting through opposing forces. Dialectically opposing forces may result from conflicting individual intentions, i.e., political processes, which are themselves constantly changing through self-reflexive choices in the course of one's own life, i.e., biographical development. At the same time, political processes and identity-formation change the rules governing operational situations, as well as the configuration of ecological, biological, and physical processes constraining these situations. Sustaining productive interrelations across asymmetrical levels requires self-constraint from higher levels to ensure a minimum degree of congruence with lower levels. Completely incongruent relations are unsustainable in the sense that higher-level entities become nonviable, whether they are individual human agents, governance regimes or entire cultural systems.

The three concepts presented in this paper support an asymmetrical conceptualization of social-ecological coupling. Traditional conceptualizations focus on relations between material and informational aspects. However, social organization cannot be reduced to material and biological processes. It involves subjective dynamics that are asymmetrically coupled with the biophysical world in the same way that ecological processes are with physical-chemical subsystems governed by the laws of thermodynamics. The centrality of power, agency and sociocultural heterogeneity in social human systems requires methods of analysis that transcend system-level structuralist analysis and situational approaches. The concept of congruence is introduced here to characterize the sustainability of dynamics occurring across asymmetrical levels of organization. The sustainability of symmetrically coupled systems is a property of the coupling itself. As implied by the work of Maturana and Varela (1980), congruence between symmetrically coupled subsystems is determined by their internal structures that have evolved in the context of the very coupling. This structural determinism, however, does not apply to asymmetrically coupled systems in which the internal structures of higher levels are emergent and relatively autonomous from lower level dynamics. Thompson and Varela (2001:421) argued that this form of coupling is a "reciprocal(but not symmetrical) relationship between global and local levels" through which the emergent, global level institutes its own domain of interaction.

Although ecological structures seem to "evolve" toward optimizing the dissipation of available exergy (Schneider and Kay 1994), socio-cultural self-organization is driven by symbolic processes that change more rapidly, with higher freedom to rearrange, recombine, and create new components. Even though biological and ecological functions determine some human cognitive capacities, socio-cultural organization emerges from symbolic dynamics barely influenced by biophysical processes. Human consciousness forms from the course of making our way through the world as individual subjects. Subjective individual freedom is a manifestation of our consciousness, reflexivity, and ability to maintain internal conversations about ourselves, as well as about the structures present and trajectories taking place at the objective level.

Sustainability in asymmetrically coupled systems requires minimum levels of congruence that must be initiated and instituted from higher levels. It is about balancing the new opportunities offered by human autonomy with the risks of losing sight that human autonomy can only flourish in the long run if it entails subjective processes that are congruently coupled with social-ecological materiality. Sustainable pathways can be understood to emerge when meaningful personal trajectories are sufficiently congruent with underlying material and informational dynamics. Making these pathways congruent may involve fostering social or ecological resilience at the material level, but it may also require ending resilience to open up opportunities for new socio-cultural processes that are both meaningful and materially sound.

Responses to this article can be read online at: http://www.ecologyandsociety.org/issues/responses. $\mathrm{php} / 7720$

\section{Acknowledgments:}

This material is based upon work supported by the National Science Foundation under Grant No. 1414052, CNH: The Dynamics of Multi-Scalar Adaptation in Megacities (PI H. Eakin). I thank project participants at ASU and UNAM for useful debates and valuable insights about the "nature" of social-ecological organization. Special thanks to Billie L. Turner II, Charles Redman, Aisling Force, and two anonymous reviewers for their exceedingly valuable contributions to the manuscript. I dedicate this paper to the late James Kay.

\section{LITERATURE CITED}

Agrawal, A. 2003. Sustainable governance of common-pool resources: context, methods, and politics. Annual Review of Anthropology 32(1):243-262. http://dx.doi.org/10.1146/annurev. anthro.32.061002.093112

Agrawal, A. 2005. Environmentality: technologies of government and the making of subjects. Duke University Press. Durham, North Carolina, USA. http://dx.doi.org/10.1215/9780822386421

Alessa, L., A. Kliskey, and M. Altaweel. 2009. Toward a typology for social-ecological systems. Sustainability: Science, Practice, and Policy 5(1):31-41.

Allen, T. F. H., and T. W. Hoekstra. 1992. Toward a unified ecology. Columbia University Press, New York, New York, USA.

Allen, T. F. H., J. A. Tainter, J. C. Pires, and T. W. Hoekstra. 2001. Dragnet ecology_ “just the facts, ma'am": the privilege of science 
in a postmodern world. Bioscience 51(6):475-485. http://dx.doi. org/10.1641/0006-3568(2001)051[0475:dejtfm]2.0.co;2

Archer, M. S. 1995. Realist social theory: the morphogenetic approach. Cambridge University. Press, Cambridge, UK. http:// dx.doi.org/10.1017/cbo9780511557675

Archer, M. S. 2003. Structure, agency and the internal conversation. Cambridge University Press, Cambridge, UK http://dx.doi. org/10.1017/cbo9781139087315

Armitage, D., C. Béné, A. T. Charles, D. Johnson, and E. H. Allison. 2012. The interplay of well-being and resilience in applying a social-ecological perspective. Ecology and Society 17 (4): 15. http://dx.doi.org/10.5751/es-04940-170415

Bateson, G. 1972. Steps to an ecology of mind. Ballantine, New York, New York, USA.

Beratan, K. K. 2007. A cognition-based view of decision processes in complex social-ecological systems. Ecology and Society 12(1): 27. [online] URL: http://www.ecologyandsociety.org/vol12/iss1/ $\underline{\operatorname{art} 271}$

Berkes, F., and C. Folke, editors. 1998. Linking social and ecological systems: management practices and social mechanisms for building resilience. Cambridge University Press, Cambridge, UK.

Berkes, F., and H. Ross. 2013. Community resilience: toward an integrated approach. Society and Natural Resources 26(1):5-20. http://dx.doi.org/10.1080/08941920.2012.736605

Bromley, D. W. 2012. Environmental governance as stochastic belief updating: crafting rules to live by. Ecology and Society 17 (3): 14. http://dx.doi.org/10.5751/es-04774-170314

Brown, K. 2014. Global environmental change I. A social turn for resilience? Progress in Human Geography 38(1):107-117. http:// dx.doi.org/10.1177/0309132513498837

Brown, K., and E. Westaway. 2011. Agency, capacity, and resilience to environmental change: lessons from human development, well-being, and disasters. Annual Review of Environment and Resources 36(1):321-342. http://dx.doi. org/10.1146/annurev-environ-052610-092905

Carpenter, S., B. Walker, J. M. Anderies, and N. Abel. 2001. From metaphor to measurement: resilience of what to what? Ecosystems 4(8):765-781. http://dx.doi.org/10.1007/s10021-001-0045-9

Chapin III, F. S., S. R. Carpenter, G. P. Kofinas, C. Folke, N. Able, W. C. Clark, P. Olsson, D. M. S. Smith, B. Walker, O. R. Young, F. Berkes, R. Biggs, J. M. Grove, R. L. Naylor, E. Pinkerton, W. Steffen, and F. J. Swanson. 2010. Ecosystem stewardship: sustainability strategies for a rapidly changing planet. Trends in Ecology and Evolution 25(4):241-249. http://dx.doi.org/10.1016/j. tree.2009.10.008

Checkland, P. 1981. Systems thinking, systems practice. John Wiley \& Sons, New York, New York, USA.

Clement, F. 2013. For critical social-ecological system studies: integrating power and discourses to move beyond the right institutional fit. Environmental Conservation 40(1):1-4. http://dx. doi.org/10.1017/s0376892912000276
Cote, M., and A. J. Nightingale. 2012. Resilience thinking meets social theory: situating social change in socio-ecological systems (SES) research. Progress in Human Geography 36(4):475-489. http://dx.doi.org/10.1177/0309132511425708

Crane, T. A. 2010. Of models and meanings: cultural resilience in social-ecological systems. Ecology and Society 15(4): 19. [online] URL: http://www.ecologyandsociety.org/voll5/iss4/ $\underline{\operatorname{art19l}}$

D'Aquino, P., and A. Bah. 2013. A participatory modeling process to capture indigenous ways of adaptability to uncertainty: outputs from an experiment in West African drylands. Ecology and Society 18(4): 16. http://dx.doi.org/10.5751/es-05876-180416

Davidson, D. J. 2010. The applicability of the concept of resilience to social systems: some sources of optimism and nagging doubts. Society and Natural Resources 23:1135-1149. http://dx.doi. org/10.1080/08941921003652940

Davidson, D. J. 2013. We still have a long way to go, and a short time to get there: a response to Fikret Berkes and Helen Ross. Society and Natural Resources 26:21-24. http://dx.doi. org/10.1080/08941920.2012.749758

Dennett, D. C. 1993. Consciousness explained. Penguin, London, UK.

Fabinyi, M., L. Evans, and S. J. Foale. 2014. Social-ecological systems, social diversity, and power: insights from anthropology and political ecology. Ecology and Society 19(4): 28. http://dx.doi. org/10.5751/es-07029-190428

Farrell, K. N., and A. Thiel. 2013. Nudging evolution? Ecology and Society 18(4): 47. http://dx.doi.org/10.5751/ES-05945-180447

Fath, B. D. S. E. Jørgensen, B. C. Patten, and M. Straškraba. 2004. Ecosystem growth and development. Biosystems 77(1-3):213-228. http://dx.doi.org/10.1016/j.biosystems.2004.06.001

Folke, C., Å. Jansson, J. Rockström, P. Olsson, S. R. Carpenter, F. S. Chapin III, A. S. Crépin, G. Daily, K. Danell, J. Ebbesson, T. Elmqvist, V. Galaz, F. Moberg, M. Nilsson, H. Österblom, E. Ostrom, A.. Persson, G. Peterson, S. Polasky, W. Steffen, B. Walker, and F. Westley. 2011. Reconnecting to the biosphere. Ambio 40 (7):719-738. http://dx.doi.org/10.1007/s13280-011-0184-y

Folke, C., L. Pritchard, Jr., F. Berkes, J. Colding, and U. Svedin. 2007. The problem of fit between ecosystems and institutions: ten years later. Ecology and Society 12(1): 30. [online] URL: http:// www.ecologyandsociety.org/vol12/iss1/art30/

Gallopín, G. C., P. Gutman, and H. Maletta. 1989. Global impoverishment, sustainable development and the environment: a conceptual approach. International Social Science Journal 121:375-397.

Geertz, C. 1984. Distinguished lecture: anti anti-relativism. American Anthropologist 86(2):263-278. http://dx.doi.org/10.1525/ aa.1984.86.2.02a00030

Gibson, C. C., E. Ostrom, and T. K. Ahn. 2000. The concept of scale and the human dimensions of global change: a survey. Ecological Economics 32(2):217-239. http://dx.doi.org/10.1016/ $\underline{\mathrm{s} 0921-8009(99) 00092-0}$ 
Glaser, M. 2006. The social dimension in ecosystem management: strengths and weaknesses of human-nature mind maps. Human Ecology Review 13(2):122.

Goldstein, B. E., A. T. Wessells, R. P. Lejano, and W. H. Butler. 2015. Narrating resilience: transforming urban systems through collaborative storytelling. Urban Studies 52(7):1285-1303. http:// dx.doi.org/10.1177/0042098013505653

Holling, C. S. 1973. Resilience and stability of ecological systems. Annual review of ecology and systematics 4(1):1-23. http://dx.doi. org/10.1146/annurev.es.04.110173.000245

Holling, C. S. 2001. Understanding the complexity of economic, ecological, and social systems. Ecosystems 4(5):390-405. http:// dx.doi.org/10.1007/s10021-001-0101-5

Hollingshead, A. B. 1940. Human ecology and human society. Ecological Monographs 10(3):354-366. http://dx.doi.org/10.2307/1948510

Horan, R. D., E. P. Fenichel, K. L. S. Drury, and D. M. Lodge. 2011. Managing ecological thresholds in coupled environmentalhuman systems. Proceedings of the National Academy of Sciences 108(18):7333-7338. http://dx.doi.org/10.1073/pnas.1005431108

Hornborg, A. 2009. Zero-sum world: challenges in conceptualizing environmental load displacement and ecologically unequal exchange in the world-system. International Journal of Comparative Sociology 50(3-4):237-262. http://dx.doi. org/10.1177/0020715209105141

Hukkinen, J. I. 2012. Fit in the body: matching embodied cognition with social-ecological systems. Ecology and Society 17 (4): 30. http://dx.doi.org/10.5751/es-05241-170430

Jones, N. A., H. Ross, T. Lynam, and P. Perez. 2014. Eliciting mental models: a comparison of interview procedures in the context of natural resource management. Ecology and Society 19 (1): 13. http://dx.doi.org/10.5751/es-06248-190113

Jørgensen, S. E., and Y. M. Svirezhev. 2004. Towards a thermodynamic theory for ecological systems. Elsevier, Oxford, UK.

Kay, J. J. 2000. Ecosystems as self-organising holarchic open systems: narratives and the second law of thermodynamics. Pages 135-160 in S. E. Jørgensen and F. Muller, editors. Handbook of ecosystems: theories and management. CRC Press, Boca Raton, Florida, USA.

Kay, J. J., H. A. Regier, M. Boyle, and G. Francis. 1999. An ecosystem approach for sustainability: addressing the challenge of complexity. Futures 31(7):721-742. http://dx.doi.org/10.1016/ s0016-3287(99)00029-4

Keck, M., and P. Sakdapolrak. 2013. What is social resilience? Lessons learned and ways forward. Erdkunde 67(1):5-19. http:// dx.doi.org/10.3112/erdkunde.2013.01.02

Levin, S. A. 1998. Ecosystems and the biosphere as complex adaptive systems. Ecosystems 1(5):431-436. http://dx.doi. org/10.1007/s100219900037

Lewontin, R. 1998. The triple helix. Harvard University Press, Cambridge, USA.
Li, T. M. 2001. Boundary work: community, market, and state reconsidered. Pages 157-179 in A. Agrawal and C. C. Gibson, editors. Communities and the environment: ethnicity, gender, and the state in community-based conservation. Rutgers University Press, New Brunswick, New Jersey, USA.

Lotka, A. J. 1945. The law of evolution as a maximal principle. Human Biology 17 (3):167-194.

Low, B., E. Ostrom, C. Simon, and J. Wilson. 2003. Redundancy and diversity: do they influence optimal management? Pages 83-114 in F. Berkes, J. Colding, and C. Folke, editors. Navigating social-ecological systems: building resilience for complexity and change. Cambridge University Press, Cambridge, UK. http://dx. doi.org/10.1017/cbo9780511541957.007

Manuel-Navarrete, D. 2013. Human-nature integration and global environmental change. Pages 305-315 in K. O'Brien, J. Wolf, and L. Sygna, editors. A changing environment for human security: new agendas for research, policy, and action. Earthscan, London, UK.

Manuel-Navarrete, D., and C. N. Buzinde. 2010. Socio-ecological agency: from 'human exceptionalism' to coping with 'exceptional' global environmental change. Pages 306-337 in M. R. Redclift and G. Woodgate, editors. The international handbook of environmental sociology. Edward Elgar, Cheltenham, UK. http:// dx.doi.org/10.4337/9781849805520.00018

Manuel-Navarrete, D., J. J. Kay, and D. Dolderman. 2004. Ecological integrity discourses: linking ecology with cultural transformation. Human Ecology Review 11(3):215-229.

Maturana, H. R. 2002. Autopoiesis, structural coupling and cognition: a history of these and other notions in the biology of cognition. Cybernetics and Human Knowing 9(3-4):5-34.

Maturana, H. R. 2008. Anticipation and self-consciousness. Are these functions of the brain? Constructivist Foundations 4 (1): $18-20$

Maturana, H. R., and F. J. Varela. 1980. Autopoiesis and cognition: the realization of the living. Reidel, Dordrecht, The Netherlands. http://dx.doi.org/10.1007/978-94-009-8947-4

Mazoyer, M., and L. Roudart. 2006. A history of world agriculture: from the neolithic age to the current crisis. Monthly Review Press, New York, New York, USA.

Miller, J. H., and S. E. Page. 2009. Complex adaptive systems: an introduction to computational models of social life. Princeton University Press, Princeton, New Jersey, USA. http://dx.doi. org/10.1515/9781400835522

Minkel, J. R. 2002. The meaning of life. New Scientist 2363:30-33.

Nicolis, G., and I. Prigogine. 1977. Self-organization in nonequilibrium systems. Wiley, New York, New York, USA.

Olsson, P., C. Folke, V. Galaz, T. Hahn, and L. Schultz. 2007. Enhancing the fit through adaptive co-management: creating and maintaining bridging functions for matching scales in the Kristianstads Vattenrike Biosphere Reserve, Sweden. Ecology and Society 12(1): 28. [online] URL: http://www.ecologyandsociety. org/vol12/iss $1 / \operatorname{art} 28 /$ 
Olsson, P., V. Galaz, and W. J. Boonstra. 2014. Sustainability transformations: a resilience perspective. Ecology and Society 19 (4): 1. http://dx.doi.org/10.5751/es-06799-190401

Ostrom, E. 1990. Governing the commons: the evolution of institutions for collective action. Cambridge University Press, Cambridge, UK http://dx.doi.org/10.1017/cbo9780511807763

Ostrom, E. 2005. Understanding institutional diversity. Princeton University Press, Princeton, New Jersey, USA.

Ostrom, E., 2009. A general framework for analyzing sustainability of social-ecological systems. Science 325 (5939):419-422. http://dx.doi.org/10.1126/science.1172133

Polanyi, M. 1968. Life's irreducible structure. Science 160 (3834):1308-1312. http://dx.doi.org/10.1126/science.160.3834.1308

Rosen, R. 1985. Anticipatory systems: philosophical, mathematical \& methodological foundations. Pergamon Press, Oxford, UK.

Schneider, E. D., and J. J. Kay. 1994. Complexity and thermodynamics: towards a new ecology. Futures 26(6):626-647. http://dx.doi.org/10.1016/0016-3287(94)90034-5

Smith, B., and A. C. Varzi. 2000. Fiat and bona fide boundaries. Philosophy and Phenomenological Research 60(2):401-420. http:// dx.doi.org/10.2307/2653492

Stengers, I. 2010. Cosmopolitics (Vol. 1). University of Minnesota Press, Minneapolis, Minnesota, USA.

Thompson, E., and F. J. Varela. 2001. Radical embodiment: neural dynamics and consciousness. Trends in Cognitive Sciences 5(10):418-425. http://dx.doi.org/10.1016/s1364-6613(00)01750-2

Trosper, R. L. 2005. Emergence unites ecology and society. Ecology and Society 10(1): 14. [online] URL: http://www. ecologyandsociety.org/vol10/iss1/art14/

Turner II, B. L. 2002. Contested identities: human-environment geography and disciplinary implications in a restructuring academy. Annals of the Association of American Geographers 92 (1):52-74. http://dx.doi.org/10.1111/1467-8306.00279

Turner II, B. L., and P. Robbins. 2008. Land-change science and political ecology: similarities, differences, and implications for sustainability science. Annual Review of Environment and Resources 33:295-316. http://dx.doi.org/10.1146/annurev. environ.33.022207.104943

Van Kerkhoff, L., and L. Lebel. 2006. Linking knowledge and action for sustainable development. Annual Review of Environment and Resources 31(1):445-477. http://dx.doi. org/10.1146/annurev.energy.31.102405.170850 